\title{
Applications of Fuzzy Linear Programming to Business Problems
}

\author{
MICHAEL GR. VOSKOGLOU \\ Mathematical Sciences, School of Technological Applications \\ University of Peloponnesus (ex T. E. I. of Western Greece\} \\ Meg. Alexandrou 1 - 26334 Patras \\ GREECE
}

\begin{abstract}
In large and complex systems it is often very difficult to find exact solutions to the Linear Programming problems with the standard techniques, since the necessary data cannot be easily determined precisely and therefore estimates of them are used in practice. Consequently, fuzzy techniques have been developed for achieving better results. In this work we introduce a simple method for solving Fuzzy Linear Programming problems with the help of Triangular Fuzzy Numbers and we apply it for solving business problems.
\end{abstract}

Key-Words: - Triangular Fuzzy Numbers (TFNs), Ranking of TFNs, Fuzzy Linear Programming (FLP), Simplex Method, Duality, Smart Learning Systems (SLS).

Received: November 15, 2019. Revised: June 1, 2020. Re-revised: June 16, 2020. Accepted: June 20, 2020. Published: June 30, 2020.

\section{Introduction}

Linear Programming $(L P)$ is a technique for the optimization (maximization or minimization) of a linear objective function subject to linear equality and inequality constraints. The feasible region of a LP problem is a convex polytope, which is a generalization of the three-dimensional polyhedron in the $\mathrm{n}$-dimensional real space $\boldsymbol{R}^{\boldsymbol{n}}$, where $\mathrm{n}$ is an integer, $\mathrm{n} \geq 2$.

A LP algorithm determines a point of the LP polytope, where the objective function takes its optimal value, if such a point exists. In 1947 George B. Dantzic invented the SIMPLEX algorithm [1], which has efficiently tackled the LP problem in most cases. Further, in 1948 Dantzic, adopting a conjecture of John von Neuman who worked on an equivalent problem in Game Theory, presented the theory of duality for LP in its typical form [2]. According to this theory every LP problem has a dual problem the optimal solution of which, if there exists, provides an optimal solution of the original problem. For general facts about the SIMPLEX algorithm we refer to Chapters 3 - 5 of [3].

LP, apart from mathematics, is widely used nowadays in business and economics, in several engineering problems, in Operations Research, etc. Frequently in practical applications many LP problems involve more than 100 and sometimes more than 1000 decision variables. In such cases the use of computer software is necessary for the solution of the problems. An important advantage of the SIMPLEX method is that it can be easily adapted to a computer program. A variety of such programs is nowadays available for commercial and academic use, like the classical LINDO, AMPL, CPLEX, MPL, PULP, GuRoBi, etc. Some of them adopt the traditional excel solver approach, while others use modelling tactics to unravel complex LP problems.

However, in large and complex systems, like the socio-economic, the biological ones, etc. ., it is often very difficult to solve accurately the LP problems with the standard techniques, since the necessary data cannot be easily determined precisely and therefore estimates of them are used in practice. The reason for this is that such kind of systems usually involve many different and constantly changing factors the relationships among which are indeterminate, making their operation mechanisms to be not clear. In order to obtain good results in such cases one may apply techniques of Fuzzy LP $(F L P)$; e.g. see $[4,5]$, etc. Computer software is also available for FLP, like the MATLAB's fuzzy logic package, the National Instrument's fuzzy toolkit, the Jana's JfuzzyLogic implementation, etc.

In the present article we introduce a simple method for solving FLP problems with the help of Triangular Fuzzy Numbers (TFNs) and we apply it for solving business problems. 
The rest of the article is formulated as follows: In Section 2 the necessary background information about TFNs is presented. In Section 3 our method for solving FLP problems is developed and is applied in Section 4 for solving business problems. The article closes with the final conclusions, which are presented in Section 5.

\section{Triangular Fuzzy Numbers}

The reader is considered to be familiar with the basics of the theory of FS and of TFNs (e.g. see [6], Chapters 4 and 7).

The following theorem helps the ranking of TFNs:

1. Theorem: The coordinates $(x, y)$ of the center of gravity (COG) of the graph of the TFN (a, b, c), with $\mathrm{a}, \mathrm{b}, \mathrm{c}$ in $\mathrm{R}, \mathrm{a}<\mathrm{b}<\mathrm{c}$, are calculated by the formulas $x=\frac{a+b+c}{3}, y=\frac{1}{3}$.

Proof: The graph of the TFN ( $a, b, c)$ is the triangle $\mathrm{ABC}$ of Figure 1, with $\mathrm{A}(\mathrm{a}, 0), \mathrm{B}(\mathrm{b}, 1)$ and $\mathrm{C}(\mathrm{c}, 0)$.

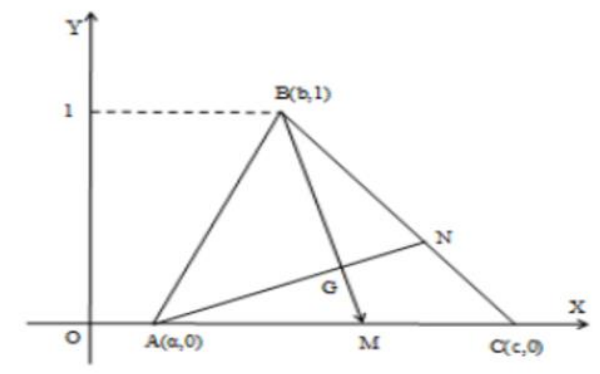

Figure 1: Graph and COG of the TFN $(a, b, c)$

The $C O G$, say $G$, of the triangle $A B C$ is the intersection point of its medians. Therefore, the proof of the Theorem is easily obtained by calculating the equations of the medians $\mathrm{AN}$ and $\mathrm{BM}$ and by solving their linear system.

For ranking the TFNs, we define (under the light of Theorem 1) the ranking function, say $r$, of a TFN A $\{\alpha, b, c)$ by

$$
\mathrm{r}(\mathrm{A})=\frac{\mathrm{a}+\mathrm{b}+\mathrm{c}}{3}(1)
$$

\section{Fuzzy Linear Programming}

The general form of a FLP problem is the following: Maximize (or minimize) the linear expression $\mathrm{F}=\mathrm{A}_{1} \mathrm{X}_{1}+\mathrm{A}_{2} \mathrm{X}_{2}+\ldots .+\mathrm{A}_{\mathrm{n}} \mathrm{X}_{\mathrm{n}}$ subject to constraints of the form $\mathrm{x}_{\mathrm{j}} \geq 0, \mathrm{~A}_{\mathrm{i} 1} \mathrm{X}_{1}+\mathrm{A}_{\mathrm{i} 2} \mathrm{X}_{2}+\ldots . .+\mathrm{A}_{\mathrm{in} \mathrm{X}_{\mathrm{n}}} \leq(\geq) \mathrm{B}_{\mathrm{i}}$, where $i=1,2, \ldots, m, j=1,2,,, n$ and $A_{j}, A_{i j}, B_{i}$ are FNs.

Here a new method is proposed for solving FLP problems with coefficients TFNs. We start with the following definition:
2. Definition: The degree of fuzziness $(D o F)$ of a TFN $A=(a, b, c)$ is defined to be the real number $\mathrm{D}=\mathrm{c}-\mathrm{a}$. We write then $\operatorname{DoF}(\mathrm{A})=\mathrm{D}$.

Then we have:

3. Theorem: Let $A(a, b, c)$ be a TFN with $\operatorname{DoF}(\mathrm{A})=\mathrm{D}$ and $\mathrm{r}(\mathrm{A})=\mathrm{R}$. Then $\mathrm{A}$ can be written as (a, 3R-2a-D, a + D), with R $-\frac{2 \mathrm{D}}{3}<\mathrm{a}<\mathrm{R}-\frac{\mathrm{D}}{3}$.

Proof: By Definition 2 we have that $\mathrm{c}=\alpha+\mathrm{D}$. Therefore, $r(A)=\frac{a+b+c}{3}=\frac{2 a+b+D}{3}=R$, which gives that $\mathrm{b}=3 \mathrm{R}-2 \mathrm{a}-\mathrm{D}$. Consequently we have that $\mathrm{a}<3 \mathrm{R}-2 \mathrm{a}-\mathrm{D}<\mathrm{a}+\mathrm{D}$. The left side of the last inequality implies that $3 a<3 R-D$, or $a<R-\frac{D}{3}$. Also its right side implies that $-3 \alpha<2 \mathrm{D}-3 \mathrm{R}$, or $\mathrm{a}>\mathrm{R}-\frac{2 \mathrm{D}}{3}$, which completes the proof.

The proposed in this work method for solving a FLP problem with coefficients TFNs involves the following steps:

- Ranking of the TFNs $A_{j}, A_{i j}$ and $B_{i}$.

- Solution of the obtained by the previous step ordinary LP problem with the standard theory.

- Conversion of the values of the decision variables in the optimal solution of the ordinary LP problem to TFNs with the desired DoF.

The last step, although it could be omitted, is useful in problems of fuzzy structure, where a fuzzy expression of their solution is often preferable than the crisp one.

\section{Applications to Business Problems}

Recently researchers have used machine learning techniques to develop through the Internet a new generation of web-based smart learning systems $(S L S)$ for various educational tasks. A SLS is a knowledge-based software used for learning and acting as an intelligent tutor in real teaching and training situations. Such systems have the ability of reasoning and of providing inferences and recommendations by using heuristic, interactive and symbolic processing and by producing results from the big data analytics ([7], Section 4). The successive phases for developing a SLS are:

- Construction of the knowledge base, involving collection, acquisition and representation of the required knowledge.

- Selection of the suitable reasoning and inference methodology, e.g. commonsense reasoning, model-based, qualitative, 
causal, geometric, probabilistic or fuzzy reasoning, etc.

- Selection of intelligent authoring shells (computer software), which allow the course instructor to easily enter the knowledge domain without requiring computer programming skills. Those shells facilitate also the entry of examples/exercises including problem statements, solution steps and explanations and the integration of suitably developed by the specialists multimedia course wear.

The next application refers to the production of SLS.

4. Example: A software company produces two types of SLS. It has been estimated that the production of a SLS of type 1 needs 2 - 3 working months (w.m.) for the construction of the knowledge base, 2.5 - $3.5 \mathrm{w}$. m. for the selection of the suitable reasoning and inference methodology and $0.75-1.25 \mathrm{w} . \mathrm{m}$. for the choice of the proper intelligent authoring shells. Also, the production of a SLS of type 2 needs $0.8-1.2,2-4$ and $1.5-2.5$ w. m. respectively, for each of the above procedures. According to the company's existing number of specialized staff, at most $20 \mathrm{w}$. m. per year can be spent for the construction of the knowledge base, at most $30 \mathrm{w}$. m. for the selection of the reasoning and inference methodology and at most $18 \mathrm{w}$. $\mathrm{m}$ for the selection of the intelligent authoring shells. If the net profit from the sale of a SLS of type 1 is between 2.7 and 3.3 hundred thousand euros and of a SLS of type 2 is between 3.8 and 4.2 hundred thousand euros ${ }^{1}$, find how many SLS's of type 1 and of type 2 should be produced per year to maximize the company's total profit. (Express the problem's optimal solution in form of TFNs with DoF equal to 1 ).

Solution: Let $x_{1}$ and $x_{2}$ be the quantities of SLS of type 1 and type 2 respectively to be produced per year. We introduce the required TFNs with the help of the problem's data in the form $\left(a, \frac{a+b}{2}, b\right)$; for example the required w. m. for the construction of the knowledge base of the SLS of type 1 is represented by the $\operatorname{TFN}(2,2.5,3)$, etc.

Then, the problem is mathematically formulated as follows:

Maximize $\mathrm{F}=(2.7,3,3.3) \mathrm{x}_{1}+(3.8,4,4.2) \mathrm{x}_{2}$,

\footnotetext{
${ }^{1}$ The profit depends upon the change of prices in the market, the salaries of the company's staff, etc.
}

subject to $\mathrm{x}_{1}, \mathrm{x}_{2} \geq 0$ and

$(2,2.5,3) \mathrm{x}_{1}+(0.8,1,1.2] \mathrm{x}_{2} \leq(19,20,21)$

$(2.5,3,3.5) \mathrm{x}_{1}+(2,3,4) \mathrm{x}_{2} \leq(29,30,31)$

$(0.75,1,1.25) \mathrm{x}_{1}+(1.5,2,2.5) \mathrm{x}_{2} \leq(15,16,17)$.

The ranking of the TFNs involved leads to the following LP maximization problem of canonical form:

Maximize $f\left(x_{1}, x_{2}\right)=3 x_{1}+4 x_{2}$, subject to $x_{1}, x_{2} \geq$ 0 and

$$
\begin{gathered}
2.5 \mathrm{x}_{1}+\mathrm{x}_{2} \leq 20 \\
3 \mathrm{x}_{1}+3 \mathrm{x}_{2} \leq 30 \\
\mathrm{x}_{1}+2 \mathrm{x}_{2} \leq 16
\end{gathered}
$$

Adding the slack variables $\mathrm{s}_{1}, \mathrm{~s}_{2}, \mathrm{~s}_{3}$ for converting the last three inequalities to equations one forms the problem's first SIMPLEX matrix, which corresponds to the feasible solution $\mathrm{f}(0,0)=0$, as follows:

$$
\left[\begin{array}{ccccc:c}
\mathrm{x}_{1} & \mathrm{x}_{2} & \mathrm{~s}_{1} & \mathrm{~s}_{2} & \mathrm{~s}_{3} & \text { Const. } \\
- & - & - & - & - & - \\
2.5 & 1 & 1 & 0 & 0 & - \\
3 & 3 & 0 & 1 & 0 & 20=\mathrm{s}_{1} \\
1 & 2 & 0 & 0 & 1 & 16=\mathrm{s}_{2} \\
- & - & - & - & - & - \\
-3 & -4 & 0 & 0 & 0 & 0=\mathrm{s}(0,0)
\end{array}\right]
$$

Denote by $\mathrm{L}_{1}, \mathrm{~L}_{2}, \mathrm{~L}_{3}, \mathrm{~L}_{4}$ the rows of the above matrix, the fourth one being the net evaluation row. Since -4 is the smaller (negative) number of the net evaluation row and $\frac{16}{2}<\frac{30}{3}<\frac{20}{1}$, the pivot element 2 lies in the intersection of the third row and second column Therefore, applying the linear transformations $\mathrm{L}_{3} \rightarrow \frac{1}{2} \mathrm{~L}_{3}=\mathrm{L}_{3}^{\prime}$ and $\mathrm{L}_{1} \rightarrow \mathrm{L}_{1}-$ $\mathrm{L}_{3}^{\prime}, \mathrm{L}_{2} \rightarrow \mathrm{L}_{2}-3 \mathrm{~L}_{3}^{\prime}, \mathrm{L}_{4} \rightarrow \mathrm{L}_{4}+4 \mathrm{~L}_{3}^{\prime}$, one obtains the second SIMPLEX matrix, which corresponds to the feasible solution $\mathrm{f}(0,8)=32$.

Repeating the same process (pivoting) one finds the third SIMPLEX matrix, which is shown in the next page. Since there is no negative index in the net evaluation row, this is the last SIMPLEX matrix. Therefore $\mathrm{f}(4,6)=36$ is the optimal solution maximizing the objective function. Further, since both the decision variables $\mathrm{x}_{1}$ and $\mathrm{x}_{2}$ are basic variables, i.e. they both participate in the optimal solution, the solution is unique. 


$$
\left[\begin{array}{ccccccc}
\mathrm{x}_{1} & \mathrm{x}_{2} & \mathrm{~s}_{1} & \mathrm{~s}_{2} & \mathrm{~s}_{3} & \mid & \text { Const. } \\
- & - & - & - & - & - & - \\
0 & 0 & 1 & -\frac{4}{3} & -\frac{3}{2} & \mid & 4=\mathrm{s}_{1} \\
1 & 0 & 0 & \frac{2}{3} & -1 & \mid & 4=\mathrm{x}_{1} \\
0 & 1 & 0 & -\frac{1}{3} & 1 & \mid & 6=\mathrm{x}_{2} \\
- & - & - & - & - & \mid & - \\
0 & 0 & 0 & \frac{2}{3} & 1 & \mid & 36=\mathrm{f}(4,6)
\end{array}\right]
$$

Converting, with the help of Theorem 3, the values of the decision variables of the above solution to TFNs with DoF equal to 1 , one finds that $\mathrm{x}_{1}=(\mathrm{a}, 11-2 \mathrm{a}, \mathrm{a}+1]$ with $\frac{10}{3}<\mathrm{a}<\frac{11}{3}$ and $\mathrm{x}_{2}=(\mathrm{a}, 17-2 \mathrm{a}, \mathrm{a}+1)$ with. $\frac{16}{3}<\mathrm{a}<\frac{17}{3}$.

Therefore a fuzzy expression of the optimal solution states that the company's maximal profit corresponds to a production between a and a +1 SLS of type 1 , with $3.33<\mathrm{a}<3.67$, and between a and $\mathrm{a}+1$ SLS of type 2 with $5.33<\mathrm{a}<5.67$.

However, taking for example $\mathrm{a}=3.5$ for $\mathrm{x}$ and $\mathrm{a}=$ 5.5 for $\mathrm{x}_{2}$ and considering the extreme in this case values of the daily construction of 4.5 SLS of type 1 and 6.5 SLS of type 2, one finds that 33 in total w. $\mathrm{m}$. are needed for the selection of the reasoning and inference methodology, whereas the maximum available w. m. are only 30 . In other words, a fuzzy expression of the solution does not guarantee that all the values of the decision variables within the boundaries of the corresponding TFNs are feasible solutions.

5. Example: A social network under construction is planning to use three types of hardware, say $F_{1}, F_{2}$ and $F_{3}$, for its function, their cost varying between $38-42,17-23$ and $55-65$ hundred euros per unit respectively. It has been estimated that each unit of $F_{1}$ has the capacity to satisfy the needs of about 1.5 2.5 hundred male and of about 4 - 6 hundred female visitors of the network per day, each unit of $F_{2}$ of about $3.2-4.8$ hundred male and $0.6-1.4$ hundred female visitors and each unit of $\mathrm{F}_{3}$ of about $1.7-2.3$ hundred male and $0.8-1.2$ hundred female visitors per day. It is expected that the network will have at least 24 hundred male and 8 hundred female visitors per day. How many units from each type should be ordered to minimize the cost of the hardware?
Solution: Let $\mathrm{x}_{1}, \mathrm{x}_{2}$ and $\mathrm{x}_{3}$ respectively be the units of the software $F_{1}, F_{2}$ and $F_{3}$ that should be ordered. Then, using TFNs the problem's mathematical model could be formulated as follows:

Minimize

$\mathrm{F}=(38,40,42) \mathrm{x}_{1}+(17,20,23) \mathrm{x}_{2}+(55,60,65) \mathrm{x}_{3}$,

subject to $\mathrm{x}_{1}, \mathrm{x}_{2}, \mathrm{x}_{3} \geq 0$ and

$(1.5,2,2.5) \mathrm{x}_{1}+(3.2,4,4.8) \mathrm{x}_{2}+(1.7,2,2.3) \mathrm{x}_{3}$

$\geq(22,24,26)$

$(4,5,6) \mathrm{x}_{1}+(0.6,1,1.4) \mathrm{x}_{2}+[0.8,1,1.2] \mathrm{x}_{3}$

$\geq(6,8,10)$

The ranking of the TFNs leads to the following LP minimization problem of canonical form:

Minimize $\mathrm{f}\left(\mathrm{x}_{1}, \mathrm{x}_{2}, \mathrm{x}_{2}\right)=40 \mathrm{x}_{1}+20 \mathrm{x}_{2}+60 \mathrm{x}_{3}$, subject to $x_{1}, x_{2}, x_{3} \geq 0$ and $2 x_{1}+4 x_{2}+2 x_{3} \geq 24$, $5 \mathrm{x}_{1}+\mathrm{x}_{2}+\mathrm{x}_{3} \geq 8$

The dual of the above problem is the following: Maximize $\mathrm{g}\left(\mathrm{z}_{1}, \mathrm{z}_{2}\right)=24 \mathrm{z}_{1}+8 \mathrm{z}_{2}$ subject to $\mathrm{z}_{1}, \mathrm{z}_{2} \geq 0$ and $2 \mathrm{z}_{1}+5 \mathrm{z}_{2} \leq 40,4 \mathrm{z}_{1}+\mathrm{z}_{2} \leq 20,2 \mathrm{z}_{1}+\mathrm{z}_{2} \leq 60$

Working similarly with Example 7 it is straightforward to check that the last SIMPLEX matrix of the dual problem is the following:

$$
\left[\begin{array}{ccccccc}
\mathrm{z}_{1} & \mathrm{z}_{2} & \mathrm{~s}_{1} & \mathrm{~s}_{2} & \mathrm{~s}_{3} & \text { Const. } \\
- & - & - & - & - & - & - \\
0 & 1 & \frac{2}{9} & \frac{1}{9} & 0 & \mid & \frac{20}{3}=\mathrm{z}_{2} \\
1 & 0 & -\frac{1}{18} & \frac{5}{18} & 0 & \mid & \frac{10}{3}=\mathrm{z}_{1} \\
0 & 0 & -\frac{1}{9} & -\frac{4}{9} & 1 & \frac{140}{3}=\mathrm{s}_{3} \\
- & - & - & - & - & - \\
0 & 0 & \frac{4}{9} & \frac{52}{9} & 0 & \mid \frac{400}{3}=g\left(\frac{10}{3}, \frac{20}{3}\right)
\end{array}\right]
$$

Therefore the solution of the corresponding minimization problem is $\mathrm{f}_{\min }=\mathrm{f}\left(\frac{4}{9}, \frac{52}{9}, 0\right)=\frac{400}{3}$. In other words, the minimal cost of the hardware is $\frac{400}{3} \approx 133$ thousand euros and will be reached by ordering $\frac{4}{9} \approx 0.44$ units of the hardware $F_{1}$, $\underline{52}$

$\overline{9} \approx 5.77$ units of the hardware $F_{2}$ and no units from the hardware $\mathrm{F}_{3}$.

Working similarly as in the previous example one could obtain a fuzzy expression of the optimal solution in form of TFNs with the desirable DoF.

6. Example: A factory produces the goods $T_{1}, T_{2}$ 
and $\mathrm{T}_{3}$ using the materials $\mathrm{C}, \mathrm{S}$ and $\mathrm{P}$. The quantities of the materials needed for producing a unit of each of the three goods are not constant depending upon their quality. The required quantities of the materials are depicted, in the form of TFNs, in Table1:

Table 1: Required quantities of the materials

\begin{tabular}{|c|c|c|c|}
\hline & $\mathrm{T}_{1}$ & $\mathrm{~T}_{2}$ & $\mathrm{~T}_{3}$ \\
\hline $\mathrm{C}$ & $(1,2,3)$ & $(5,6,7)$ & $(0.5,1,1.5)$ \\
\hline $\mathrm{S}$ & $(3,4,5)$ & $(2,3,4)$ & $(1.5,2,2.5)$ \\
\hline $\mathrm{P}$ & $(1.8,2,2.2)$ & $(0.7,1,1.3)$ & $(0.8,1,1.2]$ \\
\hline
\end{tabular}

The factory's profit from the sale of a unit of $T_{1}$ is 3 thousand euros, of a unit of $\mathrm{T}_{3}$ is 2 thousand euros, whereas from the sale of a unit of $\mathrm{T}_{2}$, the production of which becomes necessary for marketing reasons, there is a loss of 1 thousand euros.

At the end of a day the stock of the material $\mathrm{C}$ is high, so that at least 200 units of it must be used the next day, while the stock of $\mathrm{S}$ is 150 units. Further, there exists a stock of 100 units of expiring material $P$ all of which must be used the next day. Under the above conditions find with DoF equal to 0.2 which must be the next day's production of the three goods in order to maximize the factory's profit.

Solution: Let $\mathrm{x}_{1}, \mathrm{x}_{2}$ and $\mathrm{x}_{3}$ be the units of the goods $T_{1}, T_{2}$ and $T_{3}$ respectively. Then the problem is mathematically formulated as follows:

Maximize $F=3 x_{1}-x_{2}+2 x_{3}$, subject to $x_{1}, x_{2}$, $\mathrm{x}_{3} \geq 0$ and

$(1,2,3) \mathrm{x}_{1}+(5,6,7) \mathrm{x}_{2}+(0.5,1,1.5) \mathrm{x}_{3} \geq(199,200,201)$

$(3,4,5) \mathrm{x}_{1}+(2,3,4) \mathrm{x}_{2}+(1.5,2,2.5) \mathrm{x}_{3} \leq(149,150,151)$

$(0.8,1,1.2) \mathrm{x}_{1}+(0.7,1,1.3) \mathrm{x}_{2}+(0.8,1,1.2) \mathrm{x}_{3}$

$=(99,100,101)$

The ranking of the TFNs leads to the following LP maximization problem of general form ${ }^{2}$ :

Maximize $f\left(x_{1}, x_{2}, x_{2}\right)=3 x_{1}-x_{2}+2 x_{3}$, subject to $\mathrm{x}_{1}, \mathrm{x}_{2}, \mathrm{x}_{3} \geq 0$ and

$2 \mathrm{x}_{1}+6 \mathrm{x}_{2}+\mathrm{x}_{3} \geq 200$

$4 \mathrm{x}_{1}+3 \mathrm{x}_{2}+2 \mathrm{x}_{3} \leq 150$

$2 \mathrm{x}_{1}+\mathrm{x}_{2}+\mathrm{x}_{3}=100$

Adding the surplus variable $\mathrm{s}_{1}$ to the first inequality, the slack variable $s_{2}$ to the second one and the artificial variables $t_{1}$ and $t_{2}$ to the first inequality and the last equation one turns all the special constraints to equations. Next, adding by

\footnotetext{
${ }^{2}$ It is recalled that in a LP problem of general form there exists at least a constraint having the inverse sign of inequality (here $\geq$ ), while there could also exist constraints with the sign of equality.
}

members the two equations containing the artificial variables, one forms the problem's first generalized SIMPLEX matrix as follows:

$$
\left[\begin{array}{ccccccccc}
\mathrm{x}_{1} & \mathrm{x}_{2} & \mathrm{x}_{3} & \mathrm{~s}_{1} & \mathrm{~s}_{2} & \mathrm{t}_{1} & \mathrm{t}_{2} & \text { Const. } \\
- & - & - & - & - & - & - & - & - \\
2 & 6 & 1 & -1 & 0 & 1 & 0 & \mid & 200=\mathrm{t}_{1} \\
4 & 3 & 2 & 0 & 1 & 0 & 0 & \mid & 150=\mathrm{s}_{2} \\
2 & 1 & 3 & 0 & 0 & 0 & 1 & 100=\mathrm{t}_{2} \\
- & - & - & - & - & - & - & - & - \\
-3 & 1 & -2 & 0 & 0 & 0 & 0 & 0=\mathrm{f}(0,0,0) \\
- & - & - & - & - & - & - & - & - \\
4 & 7 & 4 & -1 & 0 & 1 & 1 & \mathrm{t}_{1}+\mathrm{t}_{2}=300
\end{array}\right]
$$

The rows of the artificial variables $t_{1}$ and $t_{2}$ are the, so called, anonymous rows of the above matrix. For the pivoting process, one considers all the columns containing at least one positive number in the anonymous rows, and he chooses the column having the greatest positive number in the last row (i.e. the row of $t_{1}+t_{2}$ ), which is the column of $x_{2}$.

Then, since $\frac{200}{6}<\frac{150}{3}<\frac{100}{1}$, the pivot element 6 lies in the first row. Therefore, applying the proper linear transformations among the rows of the matrix one forms the following second generalized SIMPLEX matrix:

$$
\left[\begin{array}{ccccccccc}
\mathrm{x}_{1} & \mathrm{x}_{2} & \mathrm{x}_{3} & \mathrm{~s}_{1} & \mathrm{~s}_{2} & \mathrm{t}_{1} & \mathrm{t}_{2} & \text { Const. } \\
- & - & - & - & - & - & - & - & - \\
\frac{1}{3} & 1 & \frac{1}{6} & -\frac{1}{6} & 0 & \frac{1}{6} & 0 & \mid & \frac{100}{3}=\mathrm{x}_{2} \\
3 & 0 & \frac{3}{2} & \frac{1}{2} & 1 & -\frac{1}{2} & 0 & \mid & 50=\mathrm{s}_{2} \\
\frac{5}{3} & 0 & \frac{17}{6} & \frac{1}{6} & 0 & \frac{1}{6} & 1 & \frac{200}{3}=\mathrm{t}_{2} \\
- & - & - & - & - & - & - & - & - \\
-\frac{10}{3} & 0 & -\frac{13}{6} & \frac{1}{6} & 0 & -\frac{1}{6} & 0 & -\frac{100}{3}=\mathrm{f}\left(0, \frac{100}{3}, 0\right) \\
- & - & - & - & - & - & - & - & - \\
\frac{5}{3} & 0 & \frac{17}{6} & \frac{1}{6} & 0 & -\frac{1}{6} & 1 & \frac{200}{3}=\mathrm{t}_{1}+\mathrm{t}_{2}
\end{array}\right]
$$

The pivot element $\frac{17}{6}$ lies now in the intersection of the column of $x_{3}$ and the row of $t_{2}$ and the third generalized SIMPLEX matrix is shown in the next page.

Therefore, omitting in this matrix the last row and the columns of the artificial variables one obtains the problem's first canonical SIMPLEX matrix 


$$
\left[\begin{array}{ccccccccc}
\mathrm{x}_{1} & \mathrm{x}_{2} & \mathrm{x}_{3} & \mathrm{~s}_{1} & \mathrm{~s}_{2} & \mathrm{t}_{1} & \mathrm{t}_{2} & \text { Const. } \\
- & - & - & - & - & - & - & - & - \\
\frac{4}{17} & 1 & 0 & \frac{3}{17} & 0 & \frac{3}{17} & -\frac{1}{17} & \frac{500}{17}=\mathrm{x}_{2} \\
\frac{36}{17} & 0 & 0 & \frac{7}{17} & 1 & -\frac{7}{17} & -\frac{9}{17} & \frac{250}{17}=\mathrm{s}_{2} \\
\frac{10}{17} & 0 & 1 & \frac{1}{17} & 0 & -\frac{1}{17} & -\frac{6}{17} & \frac{400}{17}=\mathrm{x}_{3} \\
\frac{35}{17} & 0 & - & 0 & \frac{5}{17} & 0 & \frac{5}{17} & \frac{13}{17} & \frac{300}{17}=\mathrm{f}\left(0, \frac{500}{17}, \frac{400}{17}\right) \\
- & - & - & - & - & - & - & - & - \\
0 & 0 & 0 & 0 & 0 & 0 & 0 & \mid & 0=\mathrm{t}_{1}+\mathrm{t}_{2}
\end{array}\right]
$$

Next, continuing the process in the standard way one finally reaches the optimal solution

$\mathrm{f}_{\max }=\mathrm{f}\left(\frac{125}{18}, \frac{250}{9}, \frac{175}{9}\right)=\frac{575}{18}$.

Converting the values $\mathrm{x}_{1}=\frac{125}{18} \approx 6.94$, $\mathrm{x}_{2}=\frac{250}{9} \approx 27.78, \mathrm{x}_{3}=\frac{175}{9} \approx 19.44$ to TFNs with DoF equal to 0.2 one finds with the help of Theorem 5 that $\mathrm{x}_{1} \approx(\mathrm{a}, 20.63-2 \mathrm{a}, \mathrm{a}+0.2)$, with $6.81<\mathrm{a}<6.87$, $\mathrm{x}_{2} \approx(\mathrm{a}, 83.13-2 \mathrm{a}, \mathrm{a}+0.2)$, with $27.64<\mathrm{a}<27.71$ and $\mathrm{x}_{3} \approx(\mathrm{a}, 58.13-2 \mathrm{a}, \mathrm{a}+0.2)$, with $19.31<\mathrm{a}<19.37$.

Taking for example the values of a equal to 6.85 , 27.7 and 19.35 respectively one finds that

$\mathrm{x}_{1} \approx(6.85,6.93,7.05), \mathrm{x}_{2} \approx(27.7,27.99,28.19)$, and $\mathrm{x}_{3} \approx(19.35,19.43,19.55)$, which are very close to the values of the decision variables in the crisp optimal solution.

In general, the smaller is the chosen DoF of the TFNs involved in the problem's optimal solution, the more creditable is the corresponding fuzzy expression of this solution.

\section{Conclusion}

A new technique was developed in this work for solving FLP problems with the help of TFNs and examples were presented illustrating its applicability to business problems. In LP problems with fuzzy structure a fuzzy expression of their solution is often preferable. This was achieved in the present work by converting the values of the decision variables in the optimal solution of the obtained ordinary LP problem to TFNs with the desired DoF.

A technique similar to that applied here for solving FLP problems can be used for solving systems of equations with fuzzy coefficients [8], as well as for solving LP problems and systems of equations with grey coefficients [9]. For interesting applications on fuzzy control the reader may also look at $[10,11]$.
References:

[1] Dantzig, G.B., Maximization of a linear function of variables subject to linear inequalities, in T.C. Koopmans (Ed.), Activity Analysis of Production and Allocation, pp. 339-347, Wiley\& Chapman - Hall, New York, London, 1951.

[2] Dantzig, G.B., Reminiscences about the origins of linear programming, Technical Report of Systems Optimization Laboratory 81-5, Department of Operations Research, Stanford University, CA, 1981.

[3] Metei, A.J. \& Jain, V., Optimization Using Linear Programming, Mercury Learning and Information, Dulles, Virginia, USA, 2019.

[4] Tanaka, H. \& Asai K., Fuzzy linear programming problems with fuzzy numbers, Fuzzy Sets and Systems, Vol. 13, 1984, pp. 110.

[5] Verdegay, J.L., A dual approach to solve the fuzzy linear programming problem, Fuzzy Sets and Systems, Vol. 14, 1984, pp. 31-141.

[6] Voskoglou, M. Gr., Finite Markov Chain and Fuzzy Logic Assessment Models: Emerging Research and Opportunities, Createspace Independent Publishing Platform, Amazon, Columbia, SC, USA, 2017.

[7] Voskoglou, M.Gr. \& Salem, A-B.M., Benefits and Limitations of the Artificial with respect to the Traditional learning of Mathematics, Mathematics, Vol. 8, 2020, Article 611.

[8] Voskoglou, M.Gr., Systems of Equations with Fuzzy Coefficients, Journal of Physical Sciences, Vol. 23, 2018, pp.77-88.

[9] Voskoglou, M.Gr., Solving Linear Programming Problems with Grey Data, Oriental Journal of Physical Sciences, Vol. 3, No. 1, 2018, pp.17-23.

[10] Yordanova, S., Slavov, M. Prokopiev, G., Disturbance Compensation in Fuzzy Logic Control of Level in Carbonisation Column for Soda Production, WSEAS Transactions on Systems and Control, Vol. 15, 2020, pp. 64-72

[11] Liping Lu, Network Controller Design and Analysis based on Fuzzy Control Theory, International Journal of Circuits, Systems and Signal Processing, Volume 13, 2019, pp. 358365

This article is published under the terms of the Creative Commons Attribution License 4.0 https://creativecommons.org/licenses/by/4.0/deed.en $\underline{\mathrm{US}}$ 